\title{
Pengomposan Limbah Baglog Jamur Tiram secara Anaerobik dengan Variasi Aktivator, Kotoran Kambing dan Urea di Desa Cisarua, Lembang Kabupaten Bandung Barat
}

\author{
Astri W Hasbiah, Yonik M Yustiani, Nabila Sari Desiriani \\ Universitas Pasundan \\ Jl. Dr. Setiabudi No. 193Bandung, Indonesia \\ E-mail:astrihasbiah@unpas.ac.id
}

\begin{abstract}
Abstrak
Usaha pertanian jamur di Desa Cisarua Lembang selain memberikan banyak manfaat juga menimbulkan permasalahan berupa limbah baglog yang tidak dikelola dan dibiarkan menumpuk. Limbah baglog atau media jamur tiram yang sudah habis masa tanamnya jika tidak dikelola dengan baik dapat mencemari lingkungan dan menjadi sumber kontaminan penyebab kegagalan budidaya jamur. Penelitian ini bertujuan untuk mengetahui campuran aktivator, pupuk kotoran kambing, dan urea yang paling baik dalam proses pengomposan limbah baglog jamur tiram yang dapat memperbaiki komposisi kompos yang dihasilkan agar kualitas kompos sesuai dengan standar kompos SNI 19-7030-2004. Pengomposan dilakukan dalam suasana anaerobik menggunakan tong tertutup. Metode pengomposan secara anaerobik dipilih karena selain dapat mengurangi volume limbah dan pencemaran air tanah, metode ini juga lebih praktis sehingga mempermudah petani jamur dalam mengelola limbah baglog yang dihasilkan. Pengomposan berlangsung selama 15 hari dengan 3 kali pengulangan. dan menggunakan 2 jenis aktivator yaitu EM4 dan Biolite. Pengolahan data pada penelitian ini menggunakan One Way ANOVA dan Uji BNt pada hasil yang memiliki perbedaan yang signifikan. Hasil pengomposan terbaik diperlihatkan pada variasi pengomposan dengan penambahan EM4 dan urea dengan nilai kadar Corganik, $\mathrm{N}$, rasio $\mathrm{C} / \mathrm{N}, \mathrm{P} 205, \mathrm{~K} 20, \mathrm{pH}$, temperatur dan kadar air berturut-turut 22,97; 0,$67 ; 45 ; 0,49 ; 0,45 ; 6.8 ; 29^{\circ} \mathrm{C}$ dan $37,13 \%$.
\end{abstract}

Kata Kunci: limbah baglog jamur tiram; pengomposan anaerobik; EM4

\begin{abstract}
The mushroom cultivation business in Cisarua-Lembang not only provides many benefits for farmers but also causes problems of untreated and accumulated bag-log waste. Unmanaged bag-log waste or expired oyster mushroom media can pollute the environment and become the source of contaminants that cause the failure of mushroom cultivation. This research aims to analyze the best mixture of composting activator, goat manure, and urea in composting process of oyster mushroom bag-log waste which can improve compost composition in accordance with compost standard SNI 19-7030-2004. Composting is conducted anaerobically using a closed barrel. Anaerobic composting method is chosen because it can reduce the volume of waste and groundwater contamination as well as more practical to facilitate mushroom farmers in managing bag-log waste generated. Composting is carried out for 15 days with 3 repetitions and using 2 types of activators namely EM4 and Biolite. Data processing in this study using One Way ANOVA and BNt Test on the results that have significant differences. The best composting result is shown on the composting variation with the addition of EM4 and urea with the value of $C$-organic, $N, C / N, P 205, K 2 O, p H$, temperature and moisture content of $22.97 ; 0.67,45,0.49,0.45,6.8,29^{\circ} \mathrm{C}$ and $37.13 \%$ respectively.
\end{abstract}

Keywords: $\quad$ oyster mushroom bag-logwaste;anaerobic composting; EM4

\section{PENDAHULUAN}

Usaha pertanian jamur di Desa Cisarua Lembang selain memberikan banyak manfaat juga menimbulkan permasalahan berupa limbah baglog.Baglog merupakan istilah lain dari media tanam 
jamur. Satu orang petani jamur tiram biasanya memiliki 500-1000 kantung dalam satu kali masa tanam dan dalam satu tahun biasanya petani jamur melakukan 4 kali penanaman. Sebuah baglog umumnya memiliki berat $1,2 \mathrm{~kg}$ dengan masa produksi selama tiga sampai empat bulan (Sulaeman, 2011). Limbah baglog atau media jamur tiram yang sudah tidak produktif jika tidak dikelola dengan baik akan menjadi sampah yang menumpuk dan mengotori lingkungan. Jamur liar yang seringkali tumbuh di gundukan limbah baglog berperan sebagai sumber kontaminan menyebabkan kegagalan budidaya jamur tiram. Jamur-jamur tersebut menghasilkan milyaran spora, Jika terbawa angin atau melalui pakaian dan anggota tubuh pekerja, dapat menyebar keseluruh penjuru ruang termasuk kedalam ruang inokulasi jamur (Susilawati dan Raharjo, 2010).

Salah satu alternatif pengolahan limbah baglog yaitu dengan memanfaatkan limbah baglog menjadi pupuk organik melalui proses pengomposan.Untuk mempercepat proses pengomposan dapat digunakan mikroba starter atau yang biasa disebut bioaktivator. Aktivator tersebut antara lain beberapa spesies mikroorganisme pengurai materi organik yang telah diisolasi dan dioptimasi, dikemas dalam berbagai bentuk dan terdapat pada keadaan inaktif, seperti Effective Microorganism (EM4), dan Biolite. EM4 merupakan mikroorganisme (bakteri) pengurai yang dapat membantu dalam pembusukan sampah organik (Suparman, 1994). Biolite adalah cairan yang merupakan sintesa bioteknologi, antara nutrisi alami dan beberapa jenis bakteri pengurai dan ragi probiotik yang bermanfaat yang memiliki fungsi yang sama dengan EM4 yaitu sebagai penyedia mikroorganisme untuk mempercepat proses dekomposisi bahan organik.

Selain penambahan aktivator untuk mempercepat pengomposan, penambahan nitrogen dapat mempengaruhi nilai $\mathrm{C} / \mathrm{N}$ bahan kompos sehingga dapat mempercepat proses pengomposan. Sumber nitrogen terdapat pada kotoran kambing dan pupuk urea. Penggunaan kotoran ternak dalam bentuk kompos sebagai pupuk organik akan memperbaiki struktur dan komposisi hara tanah.Penambahan urea sebagai pemerkaya pupuk kompos dapat meningkatkan kandungan nitrogen dan menurunkan rasio C/N hingga mendekati rasio C/N tanah yaitu 10-12 (Kurniawan, et al., 2013, dalam Simarmata, et al., 2017).

Pengomposan pada penelitian ini menggunakan metode anaerobik. Metode ini memiliki manfaat diantaranya sedikitnya tenaga yang dikeluarkan pada saat pengomposan, praktis, dan menghasilkan energi terbarukan. Metode pengomposan anaerobik tidak hanya mengurangi volume limbah dan pencemaran air tanah, tetapi juga menyediakan energi murah terbarukan seperti biogas. (Bekkering et al, 2010 dalam G. Esposito et al, 2012).

\section{METODE}

Metode penelitian yang digunakan dalam penelian ini adalah metode eksperimen dengan $3 \mathrm{kali}$ pengulangan. Tahapan penelitian yang dilakukan adalah sebagai berikut:

\section{Analisis Awal Limbah Baglog Jamur Tiram}

Pada tahap ini dilakukan pengujian kadar air, kadar abu dan unsur hara limbah baglog jamur tiram.

\section{Aktivasi Aktivator}

1. Aktivasi EM4

Aktivasi EM4 dilakukan dengan cara mengambil $20 \mathrm{ml}$ EM4 dan melarutkannya kedalam $1000 \mathrm{ml}$ larutan gula. Kemudian larutan EM4 dan gula difermentasi selama 24 jam. Setelah EM4 aktif, larutan EM4 diambil $100 \mathrm{ml}$ untuk diencerkan kedalam $2000 \mathrm{ml}$ air. 


\section{Aktivasi Biolite}

Aktivasi Biolite dilakukan dengan cara memasukan 5 sendok makan gula ke dalam botol yang berisi Biolite. Larutan Biolite dan gula kemudian didiamkan selama 24 jam. Larutan biolite yang sudah aktif kemudian diencerkan dengan $2000 \mathrm{ml}$ air.

\section{Proses Pengomposan}

Pada penelitian ini proses pengomposan limbah baglog menggunakan metode anaerobik selama 15 hari menggunakan tong tertutup. Sampel yang akan dikomposkan adalah limbah baglog yang telah dipanen 3-6 bulan.Pengomposan limbah baglog jamur tiram pada penelitian ini terdiri dari 4 variasi yaitu, EM4, EM4 + 900 gr pupuk kotoran kambing, EM4 + 50 gr urea, dan Biolite. Prosedur pengomposan dilakukan dengan cara menambahkan masing-masing variasi yang telah ditentukan ke dalam $18 \mathrm{~kg}$ limbah baglog jamur tiram. Setelah itu limbah yang telah ditambahkan aktivator, pupuk kotoran kambing dan urea diaduk agar campuran merata. Kemudian kompos diamati ph, temperatur, dan kadar air awal dan akhir.

\section{Pengukuran unsur hara}

Pengukuran unsurhara diantaranya $\mathrm{C}, \mathrm{N}$, rasio $\mathrm{C} / \mathrm{N}, \mathrm{P}_{2} \mathrm{O}_{5}$ dan $\mathrm{K}_{2} \mathrm{O}$ dilakukan di Laboratorium Kimia Agro Dinas Pertanian Tanaman Pangan Provinsi Jawa Barat.

\section{Analisis hasil pengukuran unsur hara}

Analisis hasil pengukuran unsur hara dengan menggunakan One Way ANOVA dan uji lanjut BNt apabila terdapat perbedaan yang signifikan.

\section{HASIL DAN PEMBAHASAN}

\section{Analisis Awal Limbah Baglog Jamur Tiram}

Hasil analisis awal limbah baglog dapat dilihat pada tabel dibawah ini.

Tabel 1. Hasil Analisis Unsur Hara Limbah Baglog Jamur Tiram

\begin{tabular}{cccc}
\hline No. & Parameter & Satuan & $\begin{array}{c}\text { Hasil } \\
\text { Pemeriksaan }\end{array}$ \\
\hline 1 & Kadar Air & $\%$ & 69,56 \\
\hline 2 & Kadar Abu & $\%$ & 91,06 \\
\hline 3 & $\mathrm{pH}$ & - & 8,50 \\
\hline 4 & $\mathrm{C}-0$ rganik & $\%$ & 17,93 \\
\hline 5 & $\mathrm{~N}$ & $\%$ & 0,23 \\
\hline 6 & $\mathrm{P}_{2} \mathrm{O}_{5}$ & $\%$ & 0,30 \\
\hline 7 & $\mathrm{~K}_{2} \mathrm{O}$ & $\%$ & 0,20 \\
\hline 8 & $\mathrm{C} / \mathrm{N}$ rasio & $\%$ & 78 \\
\hline
\end{tabular}

Hasil tabel analisis unsur hara diatas menunjukkan kadar air dalam limbah baglog jamur tiram tinggi yaitu 69,56\% melebihi kadar air optimum kompos yang seharusnya yaitu 40-60\%. C/N rasio pada analisa awal limbah baglog jamur tiram sangat tinggi yaitu 78 \%, sedangkan menurut SNI 19-7030-2004, $\mathrm{C} / \mathrm{N}$ rasio yang harus dicapai adalah $10-20 \%$. Oleh karena itu diperlukan penambahan $\mathrm{N}$ pada proses pengomposan agar dapat menurunkan rasio $\mathrm{C} / \mathrm{N}$. 


\section{Hasil Pengomposan Limbah Baglog Jamur Tiram}

Tabel 2 dibawah ini merupakan hasil dari pengomposan limbah baglog jamur tiram dilakukan selama 15 hari dengan metode anaerobik dengan tiga kali pengulangan.

Tabel 2. Kandungan Unsur Hara, Kadar Air, Temperatur dan pH pada Kompos Limbah Baglog

\begin{tabular}{|c|c|c|c|c|c|c|c|c|c|c|}
\hline \multirow[b]{2}{*}{ No. } & \multirow[b]{2}{*}{$\begin{array}{l}\text { Nama } \\
\text { Variasi }\end{array}$} & \multicolumn{8}{|c|}{ Parameter } & \multirow{2}{*}{$\begin{array}{c}\begin{array}{c}\text { Parameter yang } \\
\text { tidak sesuai dengan } \\
\text { SNI 19-7030-2004 }\end{array} \\
\end{array}$} \\
\hline & & $\begin{array}{c}\text { C- } \\
\text { organik } \\
(\%)\end{array}$ & $\begin{array}{c}\mathrm{N}- \\
\text { total } \\
(\%)\end{array}$ & $\begin{array}{l}\mathrm{P}_{2} \mathrm{O}_{5} \\
(\%)\end{array}$ & $\begin{array}{l}\mathrm{K}_{2} \mathrm{O} \\
(\%)\end{array}$ & $\mid \begin{array}{c}\text { Rasio } \\
\mathrm{C} / \mathrm{N}\end{array}$ & $\begin{array}{c}\text { Kadar } \\
\text { air } \\
(\%)\end{array}$ & $\mid \begin{array}{c}\text { Temperatur } \\
\left(^{\circ} \mathrm{C}\right)\end{array}$ & pH & \\
\hline 1. & EM41 & 20,68 & 0,43 & 0,32 & 0,26 & 48 & 62,44 & 25 & 6.8 & $\mathrm{P}$, rasio $\mathrm{C} / \mathrm{N}$, kadar air \\
\hline 2. & EM42 & 29,01 & 0,15 & 0,41 & 0,41 & 193 & 46,16 & 26 & 7 & Kadar N, rasio C/N \\
\hline 3. & EM43 & 29,92 & 0,16 & 0,37 & 0,38 & 187 & 49,03 & 26 & 7 & Kadar N, rasio C/N \\
\hline 4. & EM4PK1 & 20,62 & | 0,30 & 0,34 & | 0,36 & 69 & 54,47 & 31 & 5.8 & $\begin{array}{l}\text { Kadar N,rasio C/N, } \\
\text { kadar air, pH, suhu }\end{array}$ \\
\hline 5. & EM4РК2 & 22,9 & $\mid 0,27$ & 0,46 & | 0,57 & 85 & 56,32 & 29 & |6.84 & $\begin{array}{c}\text { Kadar N, rasio } \mathrm{C} / \mathrm{N} \text {, } \\
\text { kadar air }\end{array}$ \\
\hline 6. & EM4PK3 & 18,87 & | 0,26 & 0,42 & $\mid 0,45$ & 73 & 61,36 & 32 & |6.42 & $\begin{array}{l}\text { Kadar N, rasio C/N } \\
\text { kadar air, } \mathrm{pH} \text {, suhu }\end{array}$ \\
\hline 7. & EM4UREA1 & 21,61 & 0,34 & 0,43 & 0,34 & 64 & 58,16 & 28 & 6.99 & $\begin{array}{c}\text { Kadar N, rasio } \mathrm{C} / \mathrm{N} \text {, } \\
\text { kadar air }\end{array}$ \\
\hline 8. & EM4UREA2 & 32 & 0,54 & 0,43 & 0,42 & 59 & 42,23 & 27 & 6.95 & Rasio C/N \\
\hline 9. & EM4UREA3 & 22,97 & 0,67 & 0,4 & 0,45 & 45 & 37,13 & 29 & 6.8 & Rasio C/N \\
\hline 10. & BIOLITE1 & 23,28 & 0,27 & 0,34 & 0,28 & 86 & 39,45 & 27 & 6.9 & Kadar N, rasio C/N \\
\hline 11. & BIOLITE2 & 30,58 & 0,12 & 0,38 & 0,42 & 255 & 47,39 & 27 & 6.84 & Kadar N, rasio C/N \\
\hline 12. & BIOLITE3 & 27,54 & 0,16 & 0,35 & 0,44 & 172 & 49,10 & 27 & 6.95 & Kadar N, rasio C/N \\
\hline
\end{tabular}

\section{Kandungan C-organik (\%)}

Limbah baglog memiliki kadar C organik yang tinggi. Sumber karbon biasanya terdapat pada bahan-bahan organik seperti kayu, daun kering dll. Kandungan limbah baglog jamur tiram meliputi $90 \%$ serbuk gergaji, $7 \%$ bekatul, $1 \%$ kapur, $2 \%$ tapioka dan $45-60 \%$ volume air. Kandungan C organik dalam pengomposan berfungsi menyediakan energi untuk mikrorganisme yang melakukan degradasi dalam pengomposan.

Tabel 3. Hasil Statistik C-organik dari Uji One Way ANOVA

\begin{tabular}{cccc}
\hline & Sum of Squares & Df & Sig. \\
\hline $\begin{array}{c}\text { Variasi } \\
\text { Aktivator }\end{array}$ & 94.346 & 3 & 0.244 \\
\hline Galat & 147.993 & 8 & \\
\hline Total & 242.343 & 11 & \\
\hline
\end{tabular}

Tabel 3 menunjukkan hasil statistik kandungan C-organik dengan uji One Way ANOVA, diperoleh nilai signifikan $=0.244>(\alpha: 0.05)$ sehingga Ho diterima, dapat disimpulkan bahwa tidak ada perbedaan kandungan $\mathrm{C}$-organik yang signifikan akibat perbedaan variasi aktivator.

\section{Kandungan N(\%)}

Kandungan Nitrogen dalam hasil pengomposan limbah baglog dengan menggunakan berbagai aktivator mengalami peningkatan pada variasi EM4PK1, EM4PK2, EM4PK3 dan EM4UREA1, EM4UREA2, EM4UREA3.

Kenaikan kandungan nitrogen pada variasi tersebut disebabkan adanya penambahan bakteri, pupuk kandang dan urea. Pupuk urea mengandung unsur hara N sebesar $46 \%$ dengan pengertian setiap $100 \mathrm{~kg}$ mengandung $46 \mathrm{~kg}$ Nitrogen, moisture 0,5\%,kadar biuret $1 \%$. 
Tabel 4. Hasil Statistik N dari Uji One Way ANOVA

\begin{tabular}{cccc}
\hline & $\begin{array}{c}\text { Sum of } \\
\text { Squares }\end{array}$ & Df & Sig. \\
\hline Variasi Aktivator & 0.191 & 3 & 0.044 \\
\hline Galat & 0.119 & 8 & \\
\hline Total & 0.310 & 11 & \\
\hline
\end{tabular}

Tabel 4 menunjukkan hasil statistik kandungan $\mathrm{N}$ dari uji One Way ANOVA, diperoleh nilai signifikan $=0.044<(\alpha$ : 0.05) sehingga Ho ditolak, dapat disimpulkan bahwa terdapat perbedaan kandungan $\mathrm{N}$ total yang signifikan akibat perbedaan variasi aktivator. Karena terdapat perbedaan yang signifikan dibutuhkan uji lanjut atau ANOVA Post Hoc. Uji lanjut dengan menggunakan metode LSD (BNt) yang terdapat pada program. SPSS.

Tabel 5. Uji Lanjut pada Kandungan $N$ total dalam Pengomposan Limbah Baglog

Keterangan:

\begin{tabular}{cc}
\hline Variasi Aktivator & Rata-Rata \\
\hline Biolite & $0.18^{\mathrm{a}}$ \\
EM4 & $0.25^{\mathrm{a}}$ \\
EM4 + PK & $0.28^{\mathrm{a}}$ \\
EM4 +UREA & $0.52^{\mathrm{b}}$ \\
\hline
\end{tabular}

angka pada kolom yang sama diikuti oleh huruf yang sama menunjukkan tidak berbeda nyata menurut uji BNt pada taraf $5 \%$.

Kandungan nitrogen tertinggi terdapat pada campuran limbah baglog, EM4 dan urea. Urea merupakan salah satu sumber nutrisi yang mempunyai kadar nitrogen yang besar yaitu sekitar $46 \%$.

Berdasarkan hasil pengomposan kandungan $\mathrm{N}$ total dalam kompos limbah baglog tidak sesuai dengan standar kualitas kompos SNI 19-7030-2004 karena minimum kandungan nitrogen dalam kompos yang diharuskan adalah $0,40 \%$ sedangkan pada penelitian ini, beberapa variasi masih belum memenuhi standar kualitas.

\section{Kandungan C/N Rasio (\%)}

$\mathrm{C} / \mathrm{N}$ rasio pada pengomposan berfungsi sebagai indikator kematangan kompos. $\mathrm{C} / \mathrm{N}$ rasio merupakan perbandingan massa karbon dengan massa nitrogen. Tabel 6 menunjukan bahwa setiap variasi mengalami penurunan $\mathrm{C} / \mathrm{N}$ rasio kecuali variasi limbah baglog dengan Biolite. Bila $\mathrm{C} / \mathrm{N}$ rasio lebih rendah atau tinggi maka proses tidak berjalan maksimal (Rynk, et al, 1992 dalam Wildan Djaja, et al 2006). Tabel 4.9 dibawah ini menunjukkan hasil statistik dari uji One Way ANOVA, diperoleh nilai signifikan $=0.121>(\alpha: 0.05)$ sehingga Ho diterima. Dapat disimpulkan bahwa tidak ada perbedaan rasio $\mathrm{C} / \mathrm{N}$ yang signifikan akibat perbedaan variasi aktivator.

Tabel 6. Hasil Statistik Rasio C/N dari Uji One Way ANOVA

\begin{tabular}{cccc}
\hline & Sum of Squares & Df & Sig. \\
\hline $\begin{array}{c}\text { Variasi } \\
\text { Aktivator }\end{array}$ & 26627.3 & 3 & 0.131 \\
\hline Galat & 28075.3 & 8 & \\
\hline Total & 54702.667 & 11 & \\
\hline
\end{tabular}

Perubahan rasio $\mathrm{C} / \mathrm{N}$ merupakan akibat dekomposisi dan stabilisasi bahan organik saat pengomposan karena mikroorganisme menggunakan karbon sebagai sumber energi dan nitrogen 
sebagai pembentuk struktur selnya (Sulaeman, 2011). Tingginya kadar karbon pada limbah menyebabkan ktu penpeningkatan pada C/N rasio.

Penurunan C/N rasio yang belum sesuai dengan standar kualitas SNI 19-7030-2004, diduga kurangnya wagomposan sehingga membutuhkan penelitidan lebih lanjut dengan waktu pengomposan lebih lama.

\section{Kandungan $\mathrm{K}_{2} \mathbf{O}$ (\%)}

Kandungan kalium yang sesuai dengan SNI 19-7030-2004 adalah 0,20\%. Kandungan $\mathrm{K}_{2} \mathrm{O}$ dapat dilihat pada tabel 1. Tabel 7 dibawah ini menunjukkan hasil statistik dari uji One Way ANOVA, diperoleh nilai signifikan $=0.473>(\alpha: 0.05)$ sehingga Ho diterima, dapat disimpulkan bahwa tidak ada perbedaan kandungan $\mathrm{K}_{2} \mathrm{O}$ yang signifikan akibat perbedaan variasi aktivator.

Tabel 7. Hasil Statistik $\mathrm{K}_{2} \mathrm{O}$ Kandungan dari Uji One Way ANOVA

\begin{tabular}{cccc}
\hline & Sum of Squares & Df & Sig. \\
\hline Variasi & 0.020 & 3 & 0.473 \\
Aktivator & 0.056 & 8 & \\
Galat & 0.076 & 11 & \\
Total &
\end{tabular}

Kandungan kalium tertinggi terdapat pada variasi limbah baglog dengan pupuk kotoran kambing (EM4PK1, EM4PK2, EM4PK3). Pupuk kandang yang digunakan adalah kotoran kambing. Hal ini menyebabkan kandungan kalium lebih tinggi daripada variasi lainnya. Kotoran kambing memiliki kandungan kalium 1,00-1,20 \%. Berdasarkan hasil penelitian kandungan $\mathrm{K}_{2} \mathrm{O}$ seluruh variasi telah sesuai dengan standar kualitas kompos SNI 19-7030-2004.

\section{Kandungan $\mathrm{P}_{2} \mathrm{O}_{5}(\%)$}

Tabel 8 dibawah ini menunjukkan hasil statistik dari uji One Way ANOVA, diperoleh nilai signifikan $=0.111>(\alpha$ : 0.05) sehingga Ho diterima, dapat disimpulkan bahwa tidak ada perbedaan kandungan P205 yang signifikan akibat perbedaan variasi aktivator.

Tabel 8. Hasil Statistik $\mathrm{K}_{2} \mathrm{O}$ Kandungan dari Uji One Way ANOVA

\begin{tabular}{cccc}
\hline & $\begin{array}{c}\text { Sum of } \\
\text { Squares }\end{array}$ & Df & Sig. \\
\hline Variasi & 0.019 & 3 & 0.111 \\
Aktivator & 0.018 & 8 & \\
Galat & 0.037 & 11 & \\
Total & & \\
\hline
\end{tabular}

Kandungan $\mathrm{P}_{2} \mathrm{O}_{5}$ dalam pengomposan mengalami peningkatan. Kenaikan kandungan $\mathrm{P}_{2} \mathrm{O}_{5}$ tertinggi pada penelitian ini terdapat pada variasi limbah baglog, EM4 dan urea. Ketersediaan C dan N menyebabkan bakteri dan fungi berkemampuan membongkar lecithin dan asam nukleat serta membebaskan $\mathrm{P}$ sebagai $\mathrm{PO}_{4}{ }^{3-}$. Urea memiliki kandungan nitrogen sebanyak $46 \%$ lebih tinggi dibandingkan kandungan nitrogen pada kotoran kambing yang berjumlah 2,43\%. Berdasarkan penelitian ini, kandungan fosfor dalam kompos limbah baglog sudah sesuai dengan standar kualitas kompos SNI 19-7030-2004 yang mensyaratkan minimum kadar fosfor 0,10\%. 


\section{Temperatur}

Temperatur pada proses pengomposan berfungsi untuk mengetahui tingkat kematangan kompos melalui karakteristik pengomposan yang sedang berjalan. Tinggi rendahnya temperatur terjadi akibat aktivitas mikroorganime pada proses pengomposan. Pengukuran suhu dilakukan pada hari pertama pengomposan dan hari ke 15. Berikut ini temperatur proses pengomposan limbah baglog.

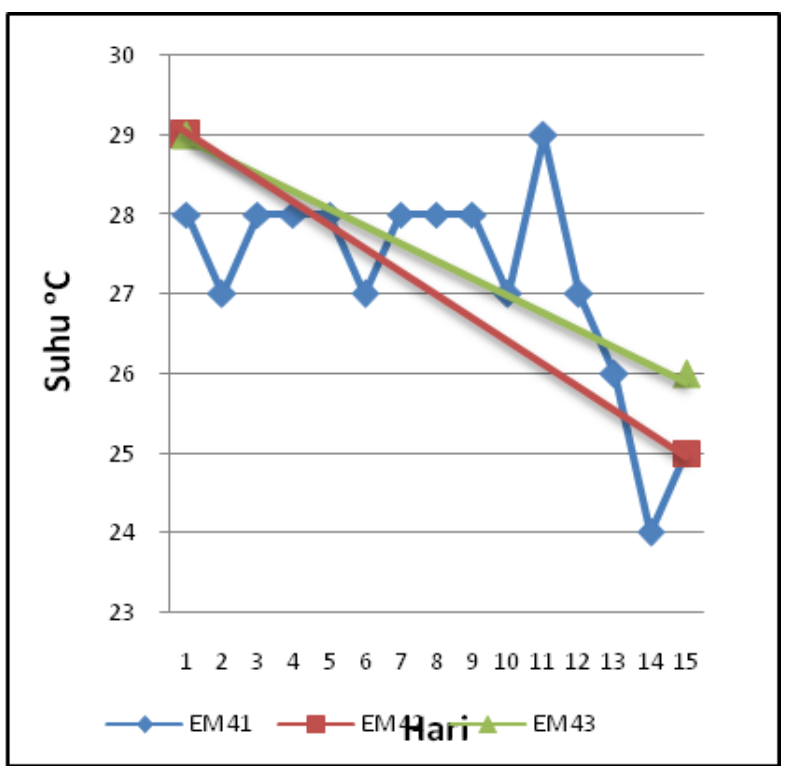

Gambar 1. Pengaruh EM4 dalam Temperatur pada Pengomposan Limbah Baglog

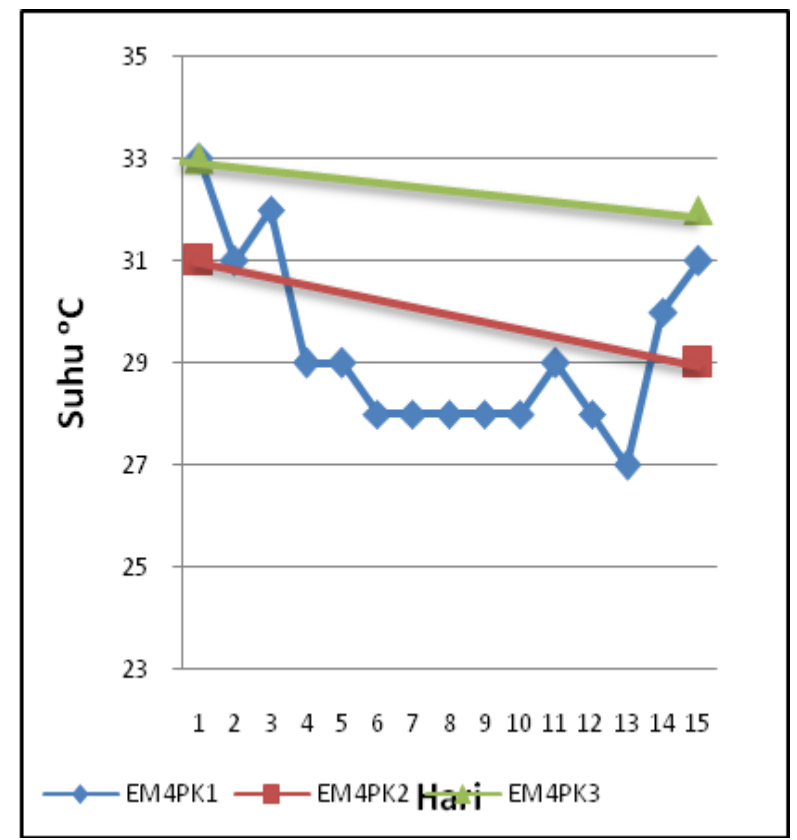

Gambar 2. Pengaruh EM4 dan Pupuk Kotoran Kambing dalam Temperatur pada Pengomposan Limbah Baglog 


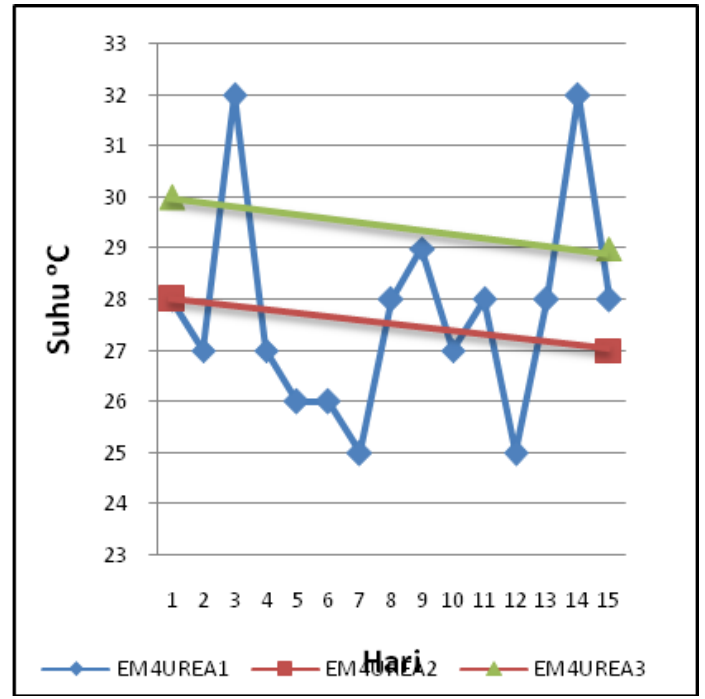

\section{Gambar 3. Pengaruh EM4 dan Urea dalam Temperatur pada Pengomposan Limbah Baglog}

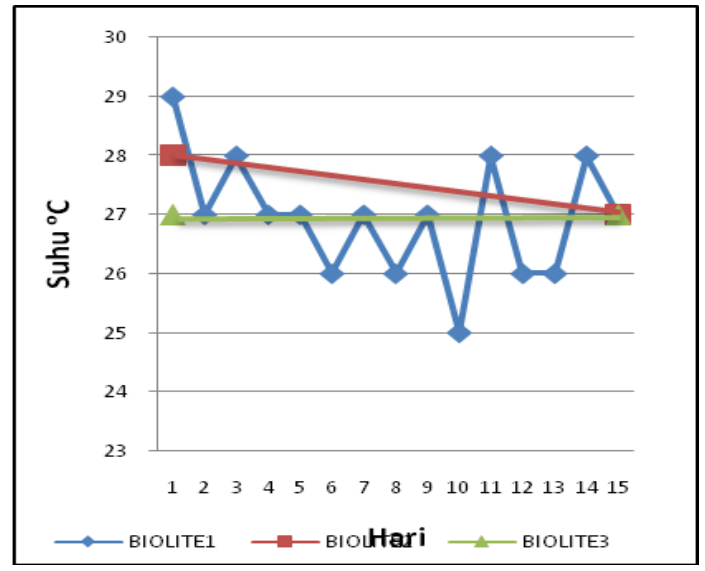

\section{Gambar 4. Pengaruh Biolite dalam Temperatur pada Pengomposan Limbah Baglog}

Pada hari pertama pengomposan masing-masing variasi memiliki suhu antara $27-29^{\circ} \mathrm{C}$. Sedangkan pada hari ke-15 masing-masing variasi mengalami penurunan suhu. Pengukuran suhu pada pengulangan pertama setiap variasi berbeda dengan pengukuran suhu pengulangan variasi kedua dan ketiga. Pengukuran suhu pengulangan pertama dilakukan selama 15 pengomposan dengan tujuan agar mengetahui suhu puncak selama pengomposan. Akan tetapi pengukuran selama 15 hari pengomposan menimbulkan resiko salah satunya yaitu penguapan kadar nitrogen. Sehingga pada pengulangan variasi kedua dan ketiga pengukuran suhu hanya pada awal pengomposan dan akhir pengomposan sehingga dalam grafik 3 pengulangan pertama berbeda dengan pengulangan kedua dan ketiga. Fluktuasi temperatur yang terlihat pada grafik terlihat tidak stabil. Perubahan temperatur disebabkan oleh aktivitas mikroorganisme. Hal ini disebabkan akibat tingginya bahan organik sebagai sumber energi mikroorganisme sehingga proses pembentukan panas terbentuk. Tinggi rendahnya temperatur juga diduga adanya penambahan oksigen pada saat melakukan pengecekan sampel. 
pH

Variasi EM4 dengan Urea dan variasi limbah baglog dengan Biolite memiliki pH kompos netral. Hal ini sejalan dengan penelitian Rizaldi (2008) dalam Sulaeman (2011), yang menunjukkan bahwa pH kompos akan mendekati netral menjelang kompos matang.

Kandungan $\mathrm{pH}$ variasi limbah baglog, EM4, dengan Urea dan variasi limbah baglog dengan Biolite telah sesuai dengan standar kualitas kompos SNI 19-7030-2004 yang mensyaratkan pH kompos 6,80 $7,49 \%$. Penurunan $\mathrm{pH}$ pada akhir pengomposan terjadi karena adanya oksidasi enzimatik menjadi $\mathrm{NO}_{3}{ }^{-}$ dan $\mathrm{SO}_{4}{ }^{2-}$. Pada reaksi enzimatik tersebut dihasilkan sejumlah kation $\mathrm{H}^{+}$(Yuwono, 2006 dalam Dini Lestari dan Emenda Sembiring 2013). Berikut grafik tingkat pH pada pengomposan limbah bglog.

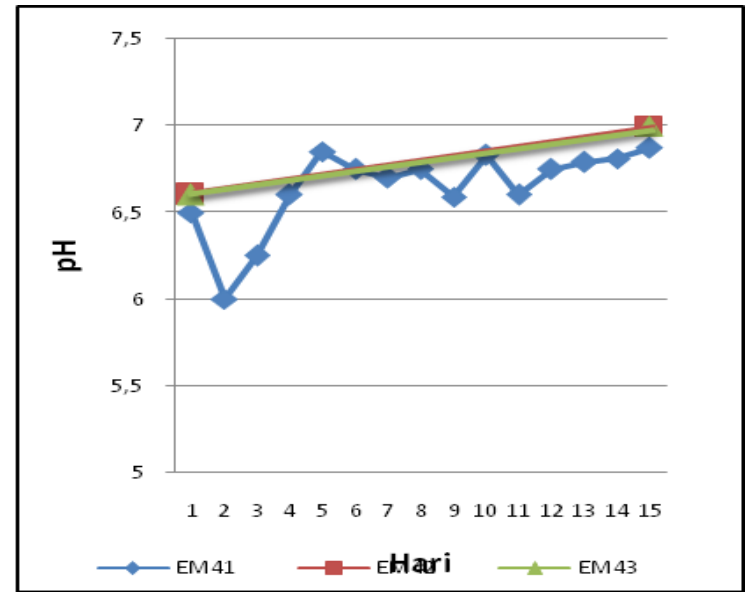

Gambar 5. Pengaruh EM4 dalam pH pada Pengomposan Limbah Baglog

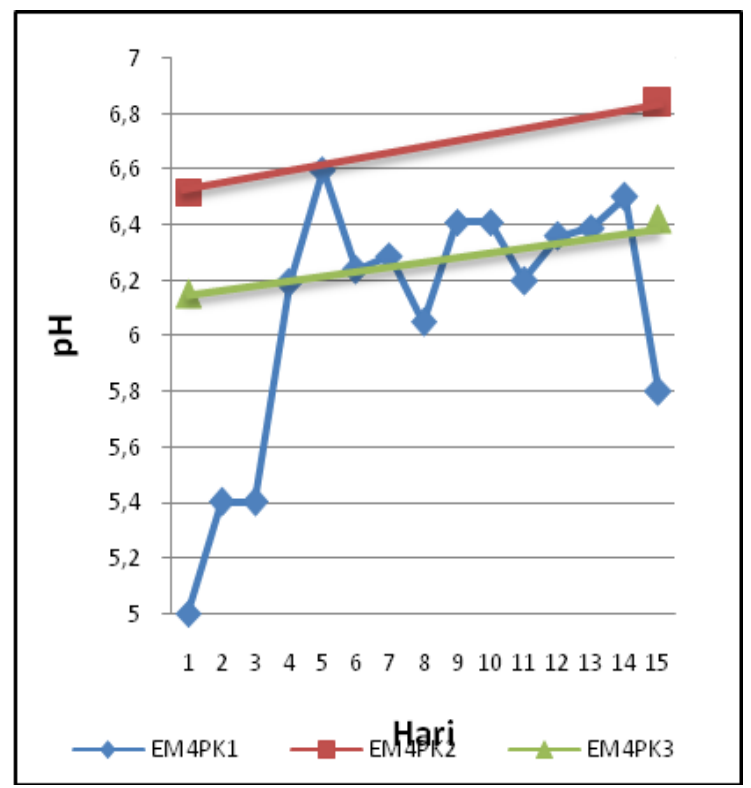

Gambar 6. Pengaruh EM4 dan Pupuk Kotoran Kambing dalam pH pada Pengomposan Limbah Baglog 


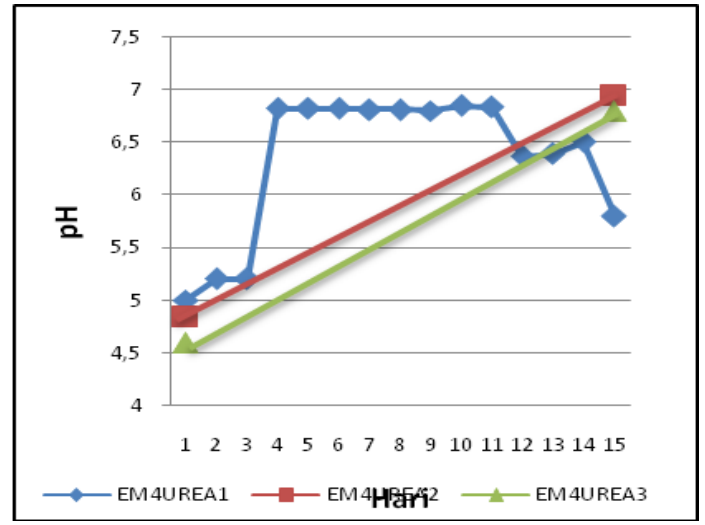

Gambar 7. Pengaruh EM4 dan Urea dalam pH pada Pengomposan Limbah Baglog

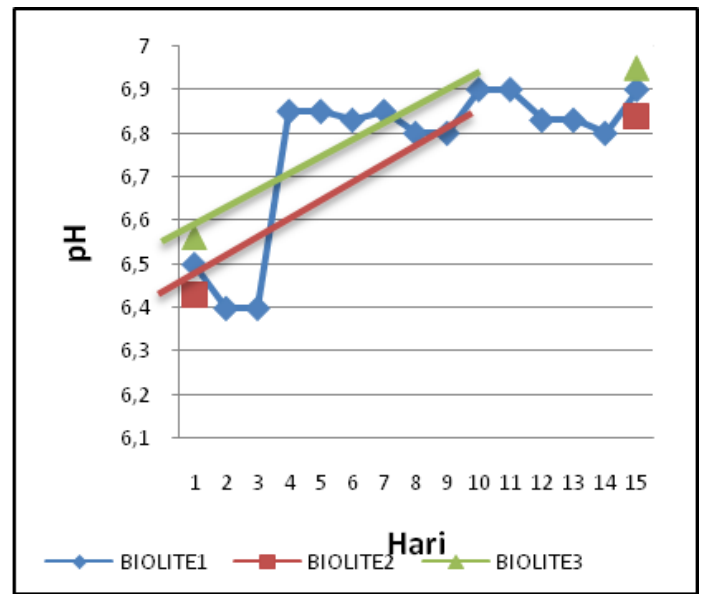

\section{Gambar 8. Pengaruh Biolite dalam pH pada Pengomposan Limbah Baglog}

Keterangan:

Pengukuran $\mathrm{pH}$ pengulangan pertama setiap variasi dilakukan selama 15 hari, sedangakan pengulangan kedua dan ketiga hanya dilakukan pada awal dan akhir kompos.

\section{Kadar Air}

Berdasarkan hasil penelitian kadar air pada variasi limbag baglog + EM4, limbah baglog + EM4 + urea, dan limbah baglog + EM4 + pupuk kandang memiliki kadar air yang sesuai dengan standar/ direkomendasikan yaitu 50-60\%. Namun, Liang dan Das Mcclendon (2003) dalam Lestari dan Sembiring (2013) menyatakan bahwa rentang 60-75\% adalah rentang kadar air dimana aktivitas mikroba maksimum.

\section{SIMPULAN}

Pengomposan dengan variasi penambahan EM4 dan Urea merupakan variasi yang paling banyak memenuhi standar parameter kompos SNI 19-7030-2004. Sehingga dapat disimpulkan bahwa penambahan EM4 dan Urea merupakan perlakuan terbaik dalam pengomposan ini. 


\section{DAFTAR PUSTAKA}

Esposito, G., Frunzo, L.,Giordano, A., Liotta, F., Panico, A., Pirozzi, F. (2012). Anaerobic co-digestion of Organic Wastes. Germany: Springer Science + Business Media B. V.

Kurniawan, H.N.A., S. Kumalaningsih, Febrianto, A. (2013). "Pengaruh Penambahan Konsentrasi Mikrobacter Alfaaf-11 (MA-11) dan Penambahan Urea terhadap Kualitas Pupuk Kompos dari Kombinasi Kulit dan Jerami Nangka dengan Kotoran Kelinci." Univeristas Brawijaya. Malang.

Lestari, D., Sembiring, E. (2013). Komposting dan Fermentasi Tandan Kosong Kelapa Sawit. Bandung: Institut Teknologi Bandung.

Simarmata, M., Syarif, S., Adriani. (2017). "Pengaruh Penambahan Urea Terhadap Bentuk Fisik dan Unsur Hara Kompos dari Feses Sapi". Jambi: Universitas Jambi.

Standar Nasional Indonesia Nomor 19-7030-(2004). Standar Kualitas Kompos. Jakarta.

Sulaeman, D. (2011). "Efek KomposLimbah Baglog Jamur Tiram Putih (Pleurotus ostreatus Jacquin) Terhadap Sifak fisik Tanah Serta Pertumbuhan Bibit MarkisaKuning (Passiflora edulis var. Flasicarpa Degner)". Bogor: Institut Pertanian Bogor.

Suparman, M. (1994). EM4 Mikrooganisme yang Efektif. Sukabumi: KTNA.

Susilawati, dan Raharjo, B. (2010). Petujuk Teknis Budidaya Jamur Tiram (Pleourotusostreatus var florida) yang RamahLingkungan (Materi Pelatihan Agribisnis bagi KMPH). BPTP. Sumatera Selatan. 